\title{
Ventilation Behavior in Residential Buildings with Mechanical Ventilation Systems across Different Climate Zones in China
}

\author{
Dayi Lai ${ }^{1,2}$, Yue $\mathrm{Qi}^{2}$, Junjie $\mathrm{Liu}^{2, *}$, Xilei $\mathrm{Dai}^{2}$, Lei Zhao ${ }^{2}$, Shen $\mathrm{Wei}^{3}$ \\ ${ }^{1}$ Department of Architecture, School of Design, Shanghai Jiao Tong University, Shanghai \\ 200240, China \\ ${ }^{2}$ Tianjin Key Laboratory of Indoor Air Environmental Quality Control, School of \\ Environmental Science and Engineering, Tianjin University, Tianjin 300072, China \\ ${ }^{3}$ The Bartlett School of Construction and Project Management, University College London \\ (UCL), London, WC1E 7HB, UK \\ *Phone: +86-22-27409500, Email: jjliu@tju.edu.cn
}

\begin{abstract}
:
A mechanical ventilation system in a residential building provides a more reliable, controllable, and comfortable means of ventilation than natural ventilation through an open window. However, the operation of a mechanical ventilation system consumes energy and may generate noise and secondary air pollutants. Thus, it is worthwhile to study residents' actual ventilation patterns. This study investigated the usage of natural and mechanical ventilation in 46 apartments across five different climate zones in China by on-site monitoring and a questionnaire survey. On average, the daily natural and mechanical ventilation durations were 11 hours and 7.2 hours, respectively. Large differences existed among climate regions and seasons. From north to south, as the climate became warmer, the usage of natural ventilation increased. From a seasonal perspective, the natural ventilation duration was the longest in summer and the shortest in winter. The trend of mechanical ventilation usage was opposite to that of natural ventilation. Generally, as the outdoor air temperature increased, the duration of natural ventilation increased and the duration of mechanical ventilation decreased. This study found that occupants prioritized their thermal comfort needs over healthy indoor air quality (IAQ). However, occupants were willing to spend money on energy when the health requirement could be met by mechanical ventilation. This study provides further understanding of occupants' ventilation behavior, and the results can serve as more accurate boundary conditions for analyses of IAQ, energy consumption, and thermal comfort in Chinese residential buildings.
\end{abstract}

\section{Keywords:}

Occupant behavior; Window opening behavior; Natural ventilation; Mechanical ventilation; Thermal comfort; Indoor air quality; 


\section{Introduction}

By supplying outdoor air to buildings and removing indoor air, ventilation can create a thermally comfortable indoor environment with acceptable indoor air quality (IAQ) [1]. Ventilation can be achieved by natural forces such as wind and thermal pressures through window openings or by artificial means through mechanical ventilation systems [2]. As reviewed by Sundell [3], an insufficient ventilation rate is associated with health problems such as inflammation, communicable respiratory infections, asthma, allergies, and sick building syndrome (SBS). Occupants' ventilation behavior, such as the opening of a window or operation of a mechanical ventilation system, strongly influences the effectiveness of ventilation.

In the past decade, an increasing number of studies have been conducted in different types of buildings in various regions to understand occupants' window-opening behavior [4-13]. For example, Yao and Zhao [4] determined a typical window operation schedule in dwellings in Beijing, China, by analyzing human-window interaction data obtained in 19 residences. A number of researchers, such as Rijal [5, 6], Andersen [7], and Pan [8], found that the proportion of occupants who opened windows was low under cold outdoor climate conditions, because of thermal comfort considerations [14-18]. In a cold climate, the short window-opening duration may not provide sufficient ventilation to maintain acceptable indoor air quality. A mechanical system provides a more reliable, controllable, and comfortable means of ventilation than opening windows. A mechanical fan can be operated continuously to ensure reliability, a filter can be used to provide control over outdoor pollutants, and a heat recovery unit can be used to reduce thermal discomfort. The capability of mechanical ventilation to maintain better indoor air quality than natural ventilation was demonstrated through a field measurement in fifteen apartments in South Korea [19]. In that study, Park [19] found that mechanical ventilation reduced the indoor to outdoor $(\mathrm{I} / \mathrm{O})$ ratios of particle number concentration by $26 \%$ for submicron particles and $65 \%$ for fine particles in comparison with natural ventilation.

Although mechanical ventilation offers several advantages over natural ventilation, it consumes energy, it may be noisy, and it can introduce secondary air pollution from the filter and duct. Therefore, it is interesting to study how people make choices between mechanical ventilation and natural ventilation when both options are available. Previous studies of ventilation behavior have focused primarily on natural ventilation via the opening of windows. Very few studies have addressed people's mechanical ventilation behavior. Andersen [7], Heebøll [20], and Gao [21] recorded window-opening behavior in rooms with mechanical ventilation, but the operation of the mechanical ventilation system was not measured. Park and Kim [22] studied mechanical ventilation behavior in apartments in South Korea in November and December of 2008 by means of a questionnaire survey. They found that 95 out of 139 respondents $(68.3 \%)$ did not use mechanical ventilation at all during the heating period in winter, and the primary reason for not doing so was the associated increase in heating energy costs. Only 10 out of 139 
respondents (7.2\%) mechanically ventilated the space for more than four hours a day. Park and Kim's investigation [22] provided a good example of the ways in which people actually use mechanical systems in their homes. However, the authors only conducted the measurement in winter in the cold climate of South Korea, and window-operation behavior was not recorded. In addition, the questionnaire survey method may not reflect realistic situations because the answers from respondents may be inaccurate and biased. In order to obtain a complete picture of ventilation behavior in residential buildings, comprehensive studies of both natural and mechanical ventilation behavior should be conducted in various climate regions and in different seasons by means of on-site monitoring.

This study reports the findings of a year-long field measurement of ventilation behavior in apartments with mechanical ventilation across five different climate zones in China. On the basis of the acquired information, a framework for analyzing the ventilation behavior in residential buildings was proposed, and suggestions for achieving healthy, thermally comfortable, and energy efficient ventilation were made.

\section{Methods}

In order to collect data for analysis of ventilation behavior, a measurement campaign was conducted in 46 apartments across five climate zones in China. This section describes the measurement campaign, the climate and season divisions within each monitored climate zone, and the data acquisition in the monitored apartments.

\subsection{Measurement campaign}

The one-year field campaign was carried out from January 1, 2017, to December 31, 2017, in 46 apartments equipped with mechanical ventilation systems across five climate zones in China. The classification of climate zones in this study was based on thermal design code for civil buildings in China (GB50176-2016) [23]. The code defines five climate zones, namely, severe cold (SC), cold (C), hot summer and cold winter (HSCW), mild (M), and hot summer and warm winter (HSWW), on the basis of the average air temperatures in the coldest and hottest months. As shown in Figure 1, the monitored apartments were in the cities of Urumqi, Shenyang, and Yingkou in the SC zone, Tianjin and Xi'an in the $\mathrm{C}$ zone, Shanghai in the HSCW zone, Kunming in the M zone, and Guangzhou, Shenzhen, and Nanning in the HSWW zone. In the monitored apartments, ventilation could be achieved by either opening windows, i.e., natural ventilation, or by operating a mechanical ventilation system. In this study, ventilation through window openings has been defined as natural ventilation (NV), and ventilation achieved by the mechanical system has been termed mechanical ventilation (MV). 


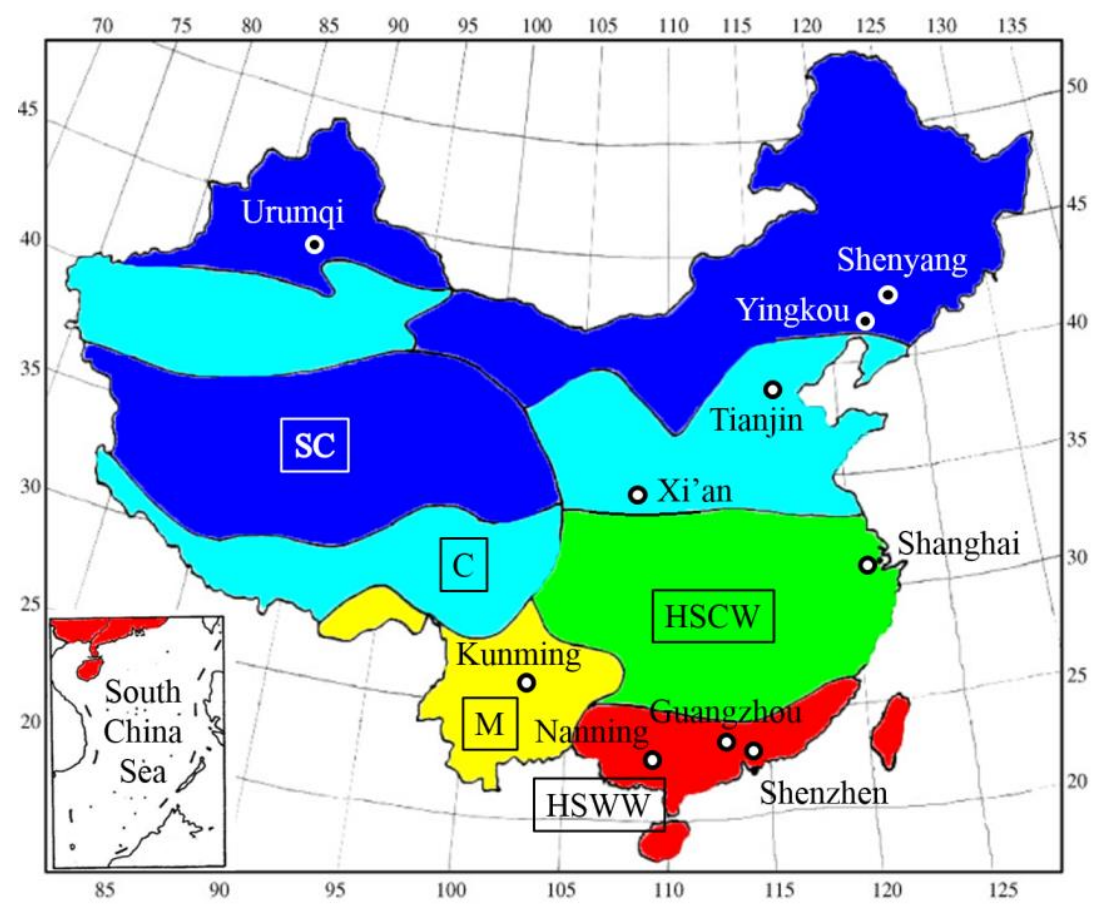

Figure 1. Illustration of the five climate zones and the monitored cities on a map of China.

The mechanical ventilation systems installed in the 46 monitored apartments can be categorized into three types: exhaust ventilation system, supply ventilation system, and energy recovery ventilation system [24]. Figure 2 provides schematics of the three systems. An exhaust ventilation system (Figure 2(a)) depressurizes the building by exhausting indoor air while make-up air infiltrates into the rooms through cracks and openings in the building shell. A supply ventilation system (Figure 2(b)) uses a fan to pressurize the building, forcing outdoor air into the building via ducts while indoor air leaks out of the building through cracks and holes in the building envelope. An energy recovery ventilation system (Figure 2(c)) provides more control than exhaust and supply ventilation systems by introducing and exhausting approximately equal amounts of outside and inside air. In addition, the energy recovery ventilation system includes a heat exchanger that uses the exhaust indoor air to warm the cold outside air. Compared with the energy recovery ventilation system, the exhaust system and the supply system are simpler and are less expensive initially. However, the introduction of untreated air directly into the building may cause thermal discomfort and may also increase the heating load. 


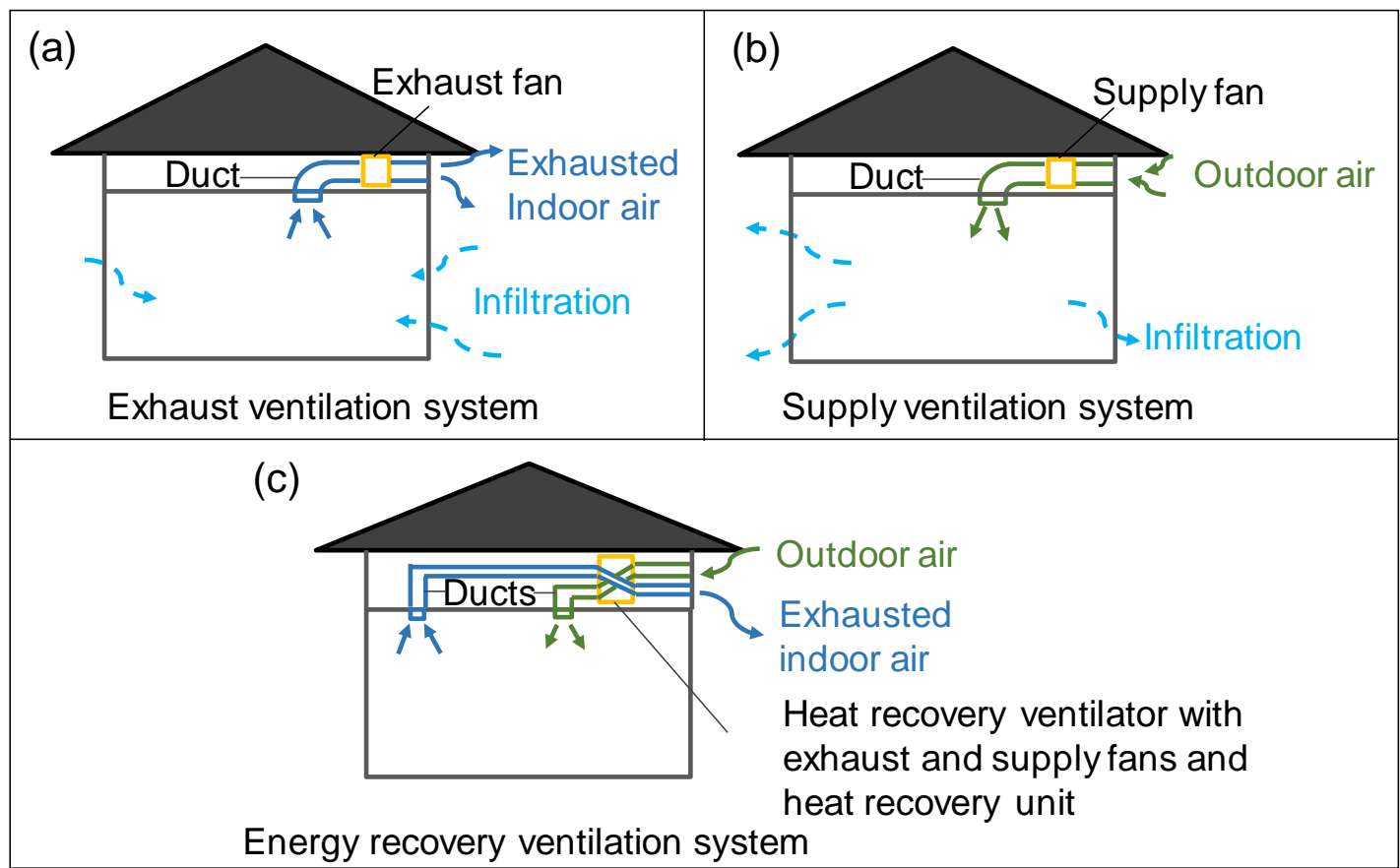

Figure 2. Schematics of (a) supply ventilation system, (b) exhaust ventilation system, and (c) energy recovery ventilation system.

Table 1 provides a summary of the mechanical ventilation systems used in all monitored households in this study. As the table shows, the numbers of monitored households were 13, 14, 7, 7, and 5 for the SC, C, HSCW, M, and HSWW regions, respectively. All the monitored apartments in the SC and HSCW regions used energy recovery systems, and all the apartments in the HSWW regions used supply ventilation systems. Among the 14 monitored households in the $\mathrm{C}$ region, five used supply ventilation systems and the rest used energy recovery systems. Exhaust ventilation systems were used in the six apartments in the $\mathrm{M}$ region. In addition to information about the mechanical ventilation systems, Table 1 lists the outdoor air temperatures in the studied cities in 2017. Generally, from north to south, the climate became warmer and the range in air temperature became narrower. Cities in the severe cold (SC) region have the coldest climate. The lowest air temperature among the cities of the $\mathrm{SC}$ region was below $-20{ }^{\circ} \mathrm{C}$. The city of Kunming, in the mild (M) region, did not experience very hot weather, as its highest air temperature was only $29{ }^{\circ} \mathrm{C}$. In contrast with Kunming, cities in the hot summer and warm winter (HSWW) region do not have a cold climate, and the temperature barely fell below $10{ }^{\circ} \mathrm{C}$. Climate variations may lead to differences in ventilation behaviors among climate zones. 
Table 1. Summary of the types of mechanical ventilation system and the outdoor air temperatures in 2017 in the studied cities. Air temperature data source: www.weather.com.cn.

\begin{tabular}{|c|c|c|c|c|c|c|c|c|c|c|}
\hline \multirow{2}{*}{$\begin{array}{l}\text { Climate } \\
\text { zone }\end{array}$} & \multirow{2}{*}{ City } & \multicolumn{4}{|c|}{$\begin{array}{l}\text { \# of monitored apartments with each } \\
\text { type of mechanical ventilation }\end{array}$} & \multirow{2}{*}{$\begin{array}{l}{ }^{*} \mathrm{~T}_{\min } \\
\left({ }^{\circ} \mathrm{C}\right)\end{array}$} & \multirow{2}{*}{$\begin{array}{l}{ }^{*} \mathrm{~T}_{\mathrm{c}, 99 \%} \\
\left({ }^{\circ} \mathrm{C}\right)\end{array}$} & \multirow{2}{*}{$\begin{array}{l}{ }^{*} \mathrm{~T}_{\mathrm{av}} \\
\left({ }^{\circ} \mathrm{C}\right)\end{array}$} & \multirow{2}{*}{$\begin{array}{l}{ }^{*} \mathrm{~T}_{\mathrm{h}, 99 \%} \\
\left({ }^{\circ} \mathrm{C}\right)\end{array}$} & \multirow{2}{*}{$\begin{array}{l}{ }^{*} \mathrm{~T}_{\max } \\
\left({ }^{\circ} \mathrm{C}\right)\end{array}$} \\
\hline & & Exhaust & Supply & $\begin{array}{l}\text { Energy } \\
\text { recovery }\end{array}$ & Total & & & & & \\
\hline \multirow{3}{*}{$\mathrm{SC}$} & Shenyang & 0 & 0 & 4 & \multirow{3}{*}{13} & -22.0 & -16.0 & 8.8 & 31.0 & 35.0 \\
\hline & Yingkou & 0 & 0 & 4 & & -20.0 & -15.0 & 9.7 & 31.0 & 34.0 \\
\hline & Urumqi & 0 & 0 & 5 & & -23.0 & -17.0 & 7.2 & 31.0 & 34.0 \\
\hline \multirow{2}{*}{$\mathrm{C}$} & Tianjin & 0 & 2 & 6 & \multirow{2}{*}{14} & -9.0 & -6.0 & 14.0 & 35.0 & 39.0 \\
\hline & Xi'an & 0 & 3 & 3 & & -5.0 & -2.0 & 15.3 & 37.0 & 41.0 \\
\hline $\mathrm{HSCW}$ & Shanghai & 0 & 0 & 7 & 7 & -5.0 & -2.0 & 16.8 & 36.0 & 39.0 \\
\hline M & Kunming & 6 & 1 & 0 & 7 & -3.0 & 3.0 & 15.3 & 26.0 & 29.0 \\
\hline \multirow{3}{*}{ HSWW } & Guangzhou & 0 & 1 & 0 & \multirow{3}{*}{5} & 6.0 & 9.0 & 23.1 & 35.0 & 38.0 \\
\hline & Shenzhen & 0 & 2 & 0 & & 7.0 & 9.0 & 23.0 & 33.0 & 36.0 \\
\hline & Nanning & 0 & 2 & 0 & & 0.0 & 9.0 & 21.8 & 34.0 & 38.0 \\
\hline
\end{tabular}

$* \mathrm{~T}_{\min }$ : minimum air temperature recorded; $\mathrm{T}_{\mathrm{c}, 99 \%}$ : air temperature of $99 \%$ accumulative frequency for cold condition; $\mathrm{T}_{\mathrm{av}}$ : annual average air temperature; $\mathrm{T}_{\mathrm{h}, 99 \%}$ : air temperature of $99 \%$ accumulative frequency for hot condition; $\mathrm{T}_{\max }$ : maximum air temperature recorded.

\subsection{Season division}

To account for the outdoor temperature differences among various climate zones, the division of seasons was based on the mean daily air temperature according to Chinese national standard QX/T 152-2012: Definition of climatic season [25]. According to this standard, winter begins and ends when the five-day averaged air temperature is less than and greater than $10{ }^{\circ} \mathrm{C}$, respectively, while summer starts and terminates when the five-day averaged air temperature is higher than and lower than $22{ }^{\circ} \mathrm{C}$, respectively. Spring and autumn occur between winter and summer. Such definitions are helpful for regional comparisons because the same seasons in different climate zones have similar outdoor air temperatures. Figure 3 shows the season divisions for the ten monitored cities. The cities in the SC region have a long winter and short spring, summer and autumn seasons. It is interesting to note that Kunming in the M region has no summer or fall, while cities in the HSWW region have no winter season. 


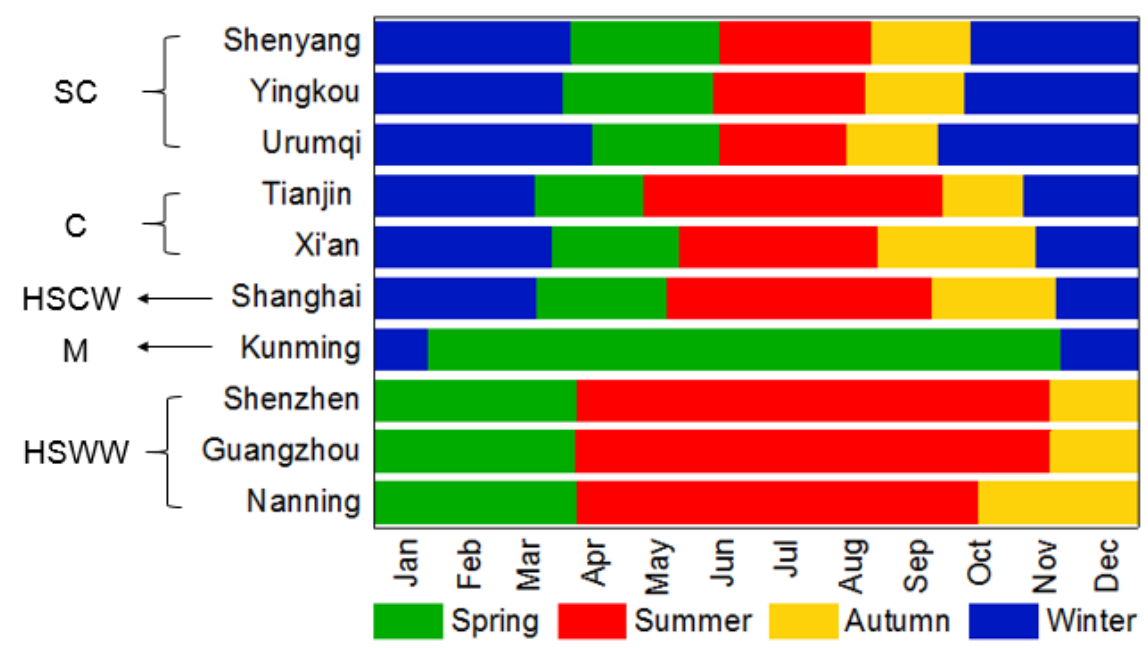

Figure 3. Season divisions for the monitored cities in the five climate zones.

\subsection{Data acquisition}

To obtain data for analysis of ventilation behavior, this study conducted a long-term on-site measurement in the monitored apartments, and questionnaires were distributed to the residents.

\subsubsection{On-site monitoring}

Four categories of parameters were collected, including mechanical ventilation operation status, window-opening and -closing actions, and relevant indoor and outdoor environmental parameters. As shown in Figure 4, the collected data was transmitted to and stored on a central server, which enabled researchers to view and download the data.

The mechanical ventilation operation status was obtained via a custom-designed recorder with a differential pressure meter and a data transmitter, as shown in Figure 4. The specification of the pressure differential meter is shown in Table 2. When the recorded differential pressure between the fan inlet and outlet was larger than $3 \mathrm{~Pa}$, the mechanical ventilation system was considered to be turned on. Otherwise, it was considered to be turned off. In order to obtain the natural ventilation behavior, the window-opening and closing actions in the main bedroom were recorded by magnetic sensors. The sensor's two magnetic induction devices were installed on the window casement and frame, as shown in Figure 4. When the distance between the two devices was greater than $2.2 \mathrm{~cm}$, the window status was considered to be open. Otherwise, the window status was considered to be closed. Opening and closing actions were recorded whenever the status of the windows changed. Every operable window in the main bedroom was monitored. The window status was considered to be closed when all windows were closed, and open when any of the windows were open. 


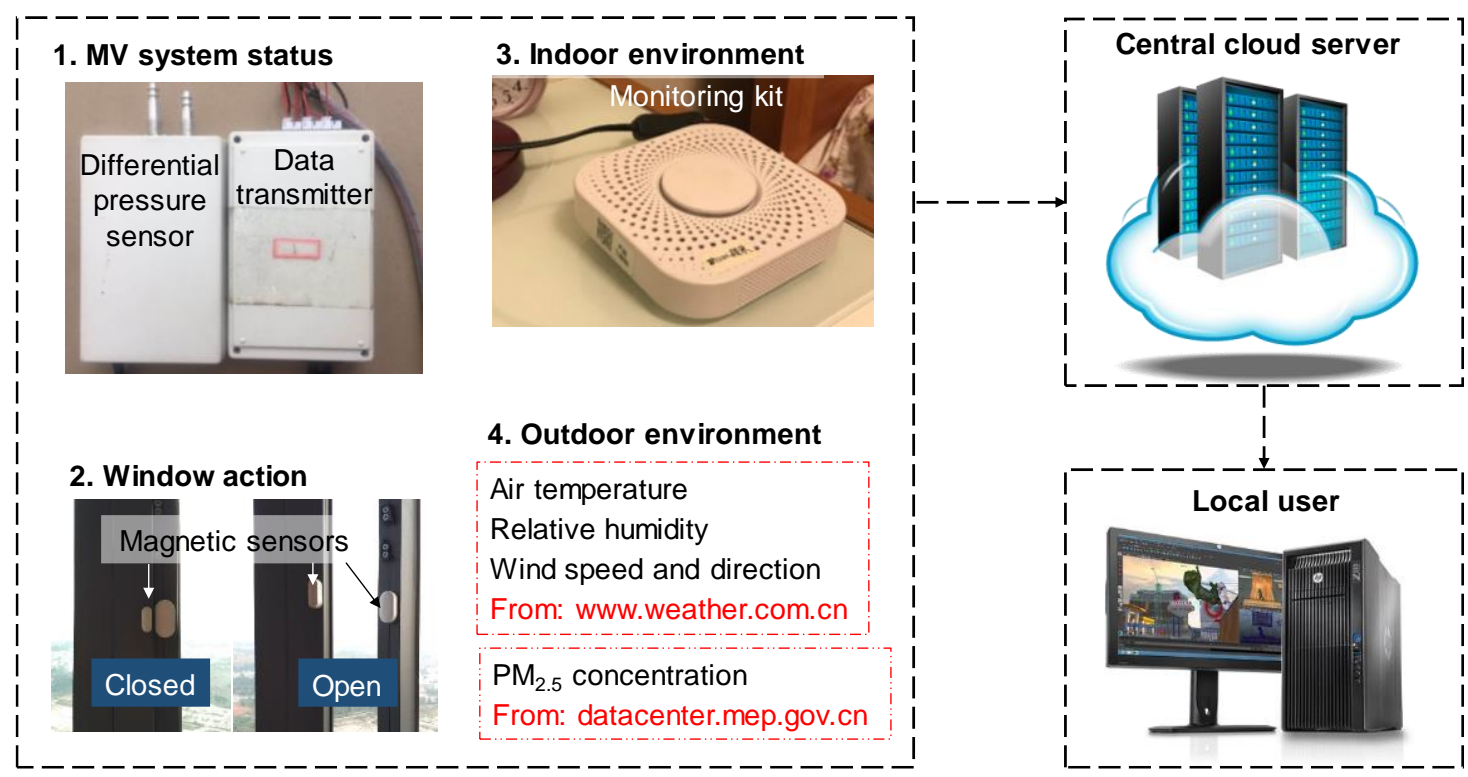

Figure 4. Data collection system for this study.

Table 2. Specification of the sensors used in the long-term monitoring campaign

\begin{tabular}{|l|l|l|}
\hline Parameter & Range & Accuracy \\
\hline Pressure difference & $0 \sim 30 \mathrm{pa}$ & $\pm 0.1 \mathrm{pa}$ \\
\hline Indoor air temperature & $-40 \sim 125^{\circ} \mathrm{C}$ & $\pm 0.3 \mathrm{~K}$ \\
\hline Indoor relative humidity & $0 \sim 100 \%$ & $\pm 3 \%$ \\
\hline $\mathrm{CO}_{2}$ & $0 \sim 2000 \mathrm{ppm}$ & $\pm 75 \mathrm{ppm}$ \\
\hline $\mathrm{PM}_{2.5}$ & $1 \sim 1000 \mu \mathrm{g} / \mathrm{m}^{3}$ & $\pm 1 \mu \mathrm{g} / \mathrm{m}^{3}$ \\
\hline TVOC & $0 \sim 3 \mathrm{ppm}$ & $\pm 5 \%$ full scale \\
\hline
\end{tabular}

The environmental parameters inside each apartment, including indoor air temperature, indoor relative humidity, $\mathrm{CO}_{2}$ concentration, indoor $\mathrm{PM}_{2.5}$ concentration, and total volatile organic compound (TVOC) concentration, were monitored with the use of an environmental monitoring kit at a 1-minute interval (Figure 4). Table 2 shows the range and accuracy of the parameters measured by the environmental monitoring kit. The kit was placed on the bedside table. The monitored $\mathrm{CO}_{2}$ concentration was used to determine whether or not the room was occupied. If, on a given day, the $\mathrm{CO}_{2}$ concentration never exceeded $460 \mathrm{ppm}$, the window status never changed, and the mechanical ventilation was not operating, then the room was deemed unoccupied on that day. The value of $460 \mathrm{ppm}$ was obtained by summing the outdoor $\mathrm{CO}_{2}$ concentration, which was $420 \mathrm{ppm}$ [7], and the instrument uncertainty, which was $40 \mathrm{ppm}$. Twohour averaged outdoor climate parameters, including outdoor air temperature, outdoor relative humidity, and outdoor wind speed and direction, were obtained from www.weather.com.cn. In addition to these meteorological parameters, outdoor $\mathrm{PM}_{2.5}$ concentration was obtained from the China National Environmental Monitoring Station, Environmental Monitoring of China 
(http://datacenter.mep.gov.cn/) every two hours. The nearest environmental monitoring station was used for each of the residences. In this study, only outdoor air temperature was used for the analysis of ventilation behavior.

\subsubsection{Questionnaire survey}

As shown in Figure 5, a questionnaire was used to collect subjective responses about residents' ventilation behavior and the reasons behind their behavior. The first section consisted of four questions that asked for the residents' preferred type of ventilation in cold, comfortable, and hot outdoor climates, and under conditions of severe outdoor pollution. The respondents chose from four answers: "NV," "MV," "Both," and "Neither." The second section consisted of two questions that allowed the respondents to provide one or more reasons for not using the mechanical system or windows for ventilation. The possible reasons for not using the mechanical system included increased energy bills, insufficient ventilation by the mechanical system, noise, and thermal discomfort. For not using the windows, the possible reasons were thermal discomfort, outdoor pollution, and noise. The respondents could also provide their own reasons by filling in the "others, please indicate" blank. The questionnaire was sent via a link to the cellphones of the residents in the monitored households. 38 questionnaires were collected. 


\section{Ventilation Behavior Questionnaire}

1. Which means of ventilation do you prefer to ventilate your apartment when the outdoor climate is cold?

(1) Natural ventilation by opening windows

(2) Mechanical ventilation

(3) Use both

(4) Use neither

2. Which means of ventilation do you prefer to ventilate your apartment when the outdoor climate is thermally comfortable?

(1) Natural ventilation by opening windows

(2) Mechanical ventilation

(3) Use both

(4) Use neither

3. Which means of ventilation do you prefer to ventilate your apartment when the outdoor climate is hot?

(1) Natural ventilation by opening windows

(2) Mechanical ventilation

(3) Use both

(4) Use neither

4. Which means of ventilation do you prefer to ventilate your apartment when the outdoor is heavily polluted?

(1) Natural ventilation by opening windows

(2) Mechanical ventilation

(3) Use both

(4) Use neither

5. Please provide your reason(s) for not using the mechanical system for ventilation? (multiple choices)

(1) Mechanical system increases energy bills

(2) Mechanical system cannot provide enough ventilation

(3) Mechanical system is noisy

(4) Mechanical system causes thermal discomfort when outdoor is cold or hot

(5) Others, please indicate:

6. Please provide your reason(s) for not using windows for ventilation? (multiple choices)

(1) Opening window causes thermal discomfort when outdoor temp is cold or hot

(2) Opening window introduces outdoor pollutants, such as smog

(3) Opening window introduces the outdoor noise

(4) Others, please indicate:

Figure 5. Ventilation behavior questionnaire used in this study. 


\section{Results}

This section first presents the ventilation durations for different climate regions. Next, the natural and mechanical ventilation durations with respect to outdoor temperature are described. The impact of system type on mechanical ventilation behavior is then examined, and the ventilation behavior patterns among households are analyzed. Finally, the results of the questionnaire survey are presented.

\subsection{General ventilation duration}

\subsubsection{Daily average ventilation duration for the whole year}

Figure 6 shows the daily average durations for natural ventilation (Figure 6(a)) and mechanical ventilation (Figure 6(b)) in various climate zones for the whole year. The average values of the daily durations for NV and MV for all apartments were 660 minutes (11.0 hours) and 429 minutes (7.2 hours), which indicates that on a general level, although mechanical ventilation was available in these monitored apartments, opening windows was the preferred means of ventilation for most of the households. However, wide variations existed among climate regions. In general, from north to south, as the climate became warmer, the duration of natural ventilation increased and that of mechanical ventilation decreased. The average durations for natural ventilation were 260 minutes, 454 minutes, 603 minutes, 606 minutes, and 776 minutes in the $\mathrm{SC}, \mathrm{C}, \mathrm{HSCW}, \mathrm{M}$, and HSWW regions, respectively. The average durations for mechanical ventilation were 656 minutes, 412 minutes, 655 minutes, 171 minutes, and 75 minutes in the $\mathrm{SC}, \mathrm{C}, \mathrm{HSCW}, \mathrm{M}$, and HSWW regions, respectively. The outdoor climate may be the main factor in the regional variations. The colder the outside temperature, the greater the discomfort that would be caused by introducing outdoor air into the room through an open window, and the shorter the duration of natural ventilation.
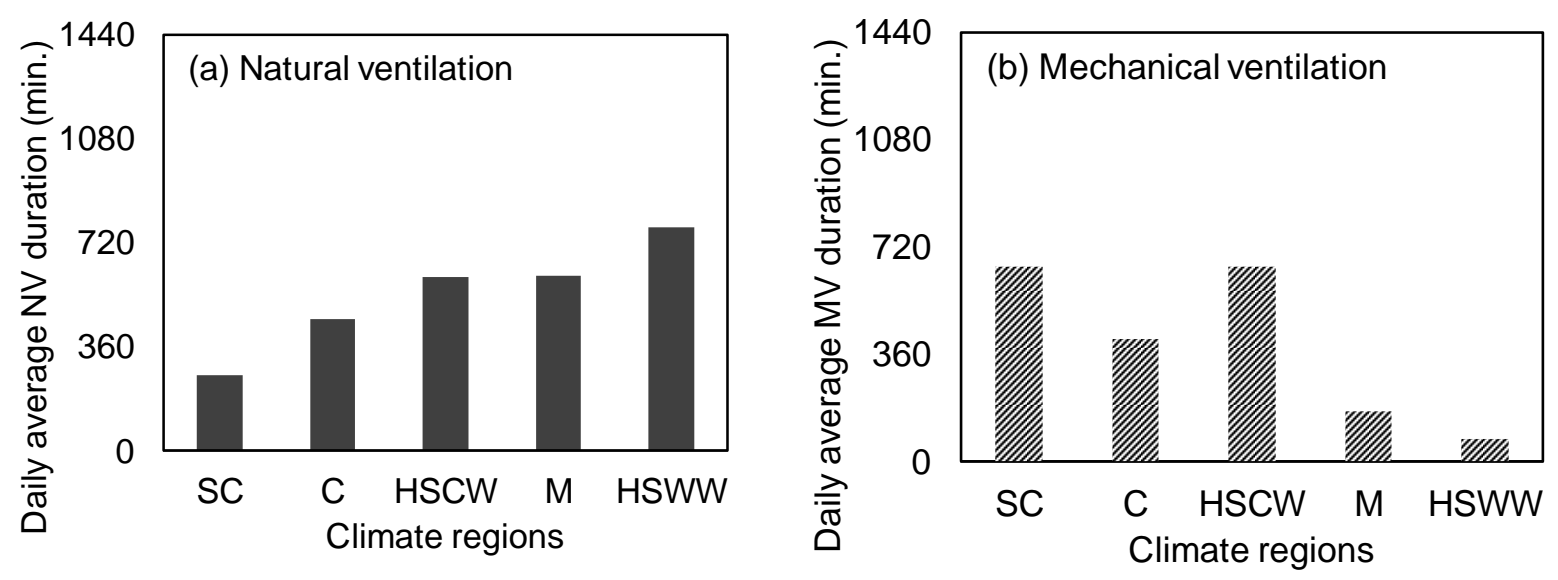

Figure 6. Averaged daily ventilation duration for the whole year in different climate regions for (a) natural ventilation and (b) mechanical ventilation.

In the monitored apartments in this investigation, the residents in cold climates compensated 
for the shorter duration of natural ventilation by operating mechanical ventilation systems. In climate regions with suitable conditions for natural ventilation, such as M and HSWW, the mechanical ventilation durations were much lower than in other regions. It is noteworthy that the averaged MV duration in the C region was noticeably shorter than in the SC and HSCW regions. Five of the 14 monitored apartments in the $\mathrm{C}$ region used supply ventilation systems that supplied outdoor air directly into the room, which may have caused thermal discomfort and reduced the overall usage. Further analysis of the impact of mechanical ventilation system type on ventilation behavior will be presented in Subsection 3.3. It was also interesting to find that, although the climate of the HSCW region was not as cold as that of the SC region, the monitored apartments in HSCW used MV as much as the apartments in the SC region. The reason may be the income of residents. According to the National Bureau of Statistics of China [26], the 2016 annual disposable incomes of urban residents per capita in Shanghai, Shenyang, Urumqi, and Yingkou were 8552 U.S. Dollars (USD), 5348 USD, 4670 USD, and 4028 USD, respectively. The higher income of Shanghai residents in the HSCW region made them less sensitive to the operating costs of the mechanical ventilation systems than were residents of SC cities.

\subsubsection{Daily average ventilation duration in the different seasons}

By breaking down the results of Figure 6 into different seasons, Figure 7 shows a clear seasonal pattern in natural ventilation and mechanical ventilation durations. Generally, summer and winter were the seasons with the longest and shortest natural ventilation durations, respectively. The seasonal climate difference can be attributed to the variations in seasonal ventilation duration. In winter, the penetration of cold outdoor air through window openings can cause cold thermal discomfort. However, in summer, when the climate is warm, opening a window can increase the air movement in the room, thus raising the acceptable indoor air temperature limit [27]. As shown in Figure 7, to compensate for the reduced natural ventilation in winter, the duration of mechanical ventilation in winter was usually long. Summer generally had the shortest MV durations among all seasons. The NV durations in spring were shorter than those in autumn, and the MV durations in spring were longer than those in autumn. When the seasons changed, people needed time to adapt their behavior, and thus their ventilation behavior in the new season followed that of the previous season. In other words, the ventilation duration in spring followed the trend in winter, and the autumn duration followed the trend in summer. 

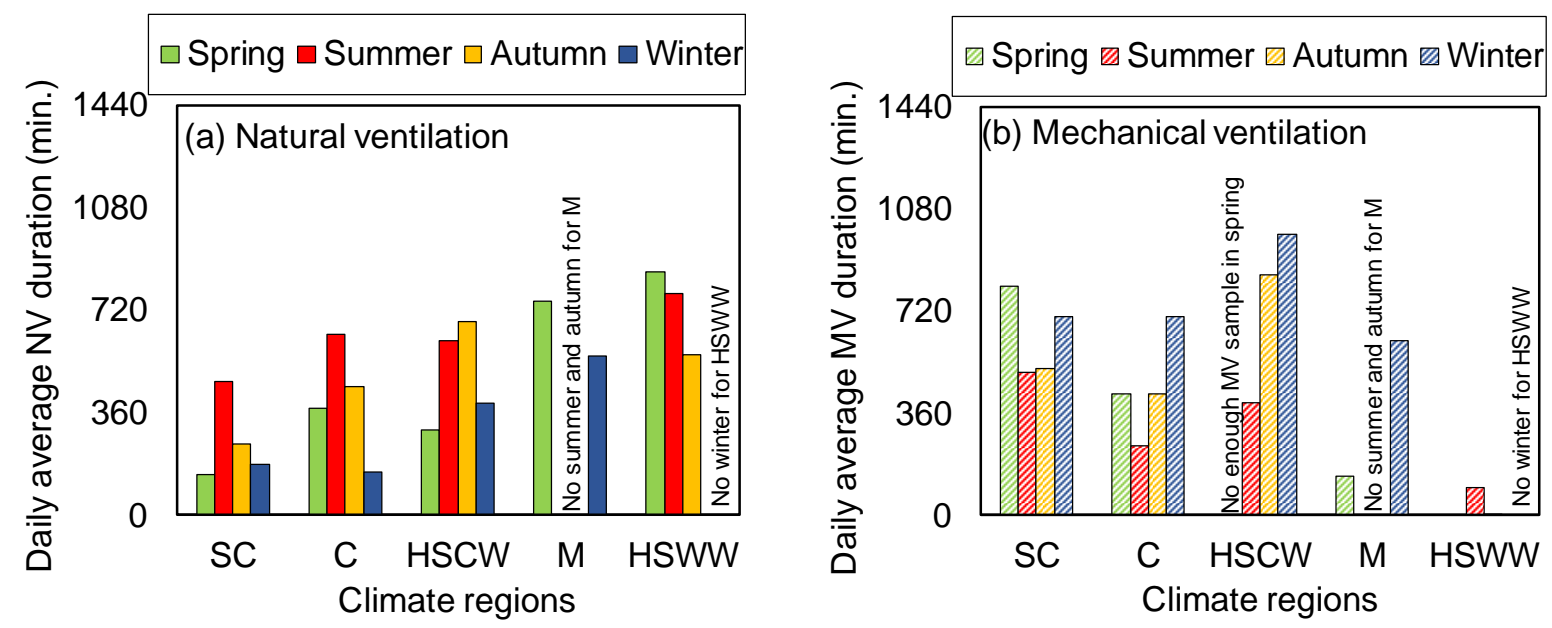

Figure 7. Averaged daily ventilation duration for different seasons in various climate regions for (a) natural ventilation and (b) mechanical ventilation.

\subsection{Influence of outdoor air temperature on ventilation duration}

\subsubsection{Influence of outdoor air temperature on natural ventilation duration}

Since the outdoor air temperature is a key indicator of climate, this section further analyzes the impact of outdoor air temperature on natural and mechanical ventilation durations. Figure 8 plots the daily mean natural ventilation duration against daily mean outdoor air temperature, by computing the average NV duration for every $2 \mathrm{~K}$ daily mean outdoor air temperature. The window-opening duration increased as the outdoor environment became warmer. Generally speaking, the duration started to decrease when the daily mean outdoor air temperature rose above $26{ }^{\circ} \mathrm{C}$. This may have been due to the use of air conditioners when the outdoor air temperature exceeded a certain value. When the natural ventilation duration under the same daily average outdoor air temperature for various climate regions is examined, it is interesting to find that the duration increased from north to south. This regional difference in NV duration may be the result of residents' long-term exposure to the environment. For example, during the long, cold winter, residents in the SC region tended to close their windows to avoid severe cold discomfort. When the outdoor climate became warmer, the residents in the SC region were slow in changing their habits and opening window for longer periods of time. 


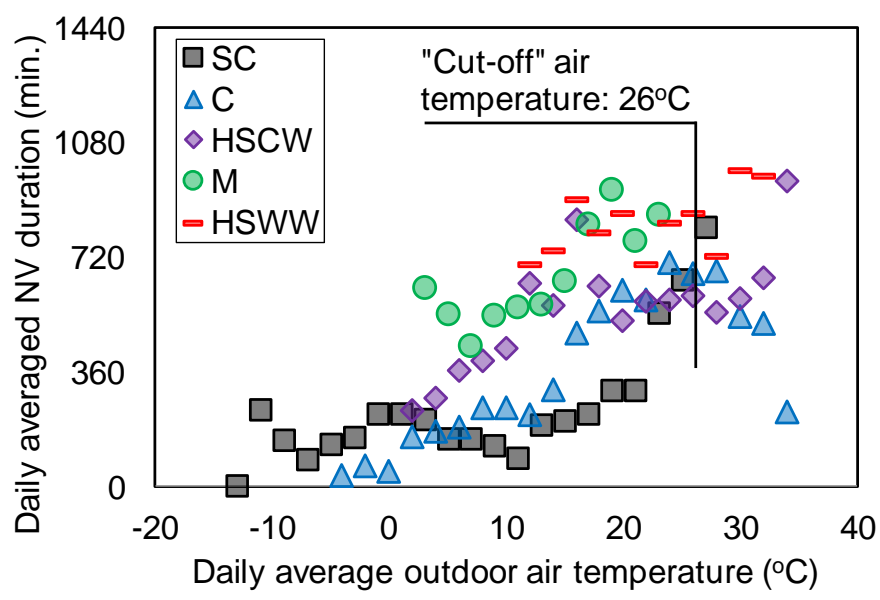

Figure 8. Natural ventilation durations under different daily average outdoor air temperatures in different climate regions.

\subsubsection{Influence of outdoor air temperature on mechanical ventilation duration}

Following a similar method to the one that generated Figure 8, Figure 9 depicts the daily average mechanical ventilation duration against the daily average outdoor air temperature. In an opposite manner to the relationship between outdoor air temperature and natural ventilation duration, the daily average MV duration decreased as the daily average outdoor air temperature increased. Energy saving is a possible reason for the reduction in MV duration. When the outdoor air temperature was suitable, people preferred NV over MV to reduce energy costs. Under the same daily average air temperature, differences in the MV duration among climate regions can be observed. However, the trend of MV duration among climate zones was not as clear as that of NV duration. Two factors may have influenced the results, as has already been discussed in Section 3.1. First, the high income of residents in the HSCW region made them less sensitive to energy costs of the MV system, and thus they frequently used the system. Second, the five apartments in the $\mathrm{C}$ region that did not use an energy recovery system had lower overall MV duration. In the SC region, the rate of decrease in the MV duration against the daily average outdoor air temperature was not as fast as the rate of decrease in other regions. The greater inertia of SC residents in changing their MV behavior corresponded to their slower adoption of window-opening behavior. Residents of the SC region could save energy by using more $\mathrm{NV}$ in place of MV under suitable outdoor conditions. In the HSWW region, mechanical ventilation was used only when the daily average temperature was between 18 and $26{ }^{\circ} \mathrm{C}$, and it was used at a very low level. 


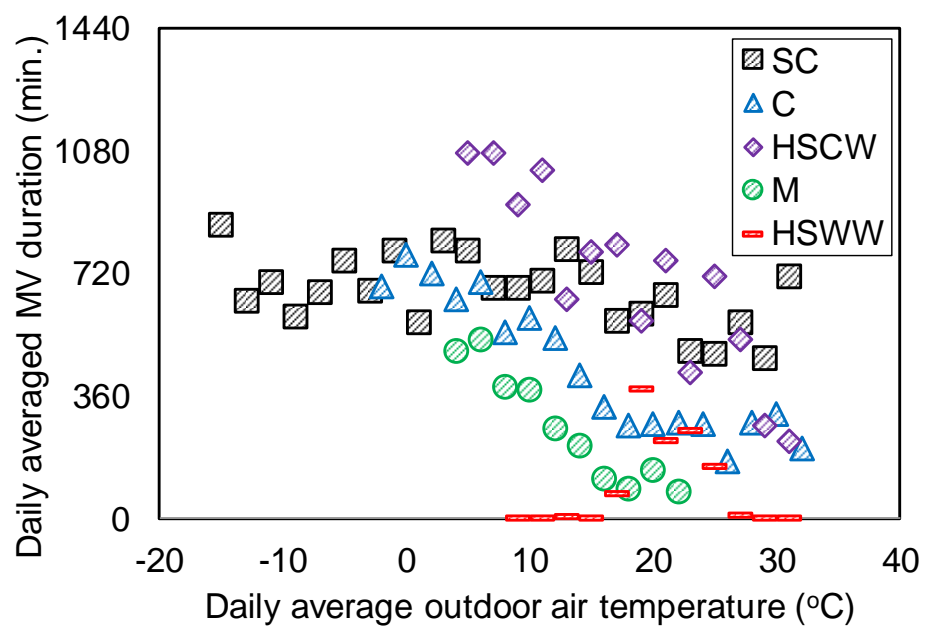

Figure 9. Mechanical ventilation durations under different daily average outdoor air temperatures in different climate regions.

\subsection{Impact of different system types on mechanical ventilation duration}

Two types of mechanical ventilation system, a supply system $(\mathrm{N}=5)$ and an energy recovery system $(\mathrm{N}=9)$, were used in the monitored apartments in the cold climate region. Figure 10 examines the impact of system type on the relationship between ventilation duration and daily average outdoor air temperature. According to Figure 10(a), the average natural ventilation duration was similar for the two types of apartment. However, a large difference was observed for the mechanical ventilation duration between the apartments with supply and energy recovery systems, as shown in Figure 10(b). Energy recovery ventilation systems were heavily used under cold outdoor temperatures, and the usage decreased when the outdoor environment became warm. In contrast, the supply ventilation systems were seldom used in cold weather, but a slight increase was found when the daily average outdoor air temperature surpassed $18{ }^{\circ} \mathrm{C}$. The infrequent usage of the supply system is reasonable because directly introducing cold outdoor air into a building would cause thermal discomfort.
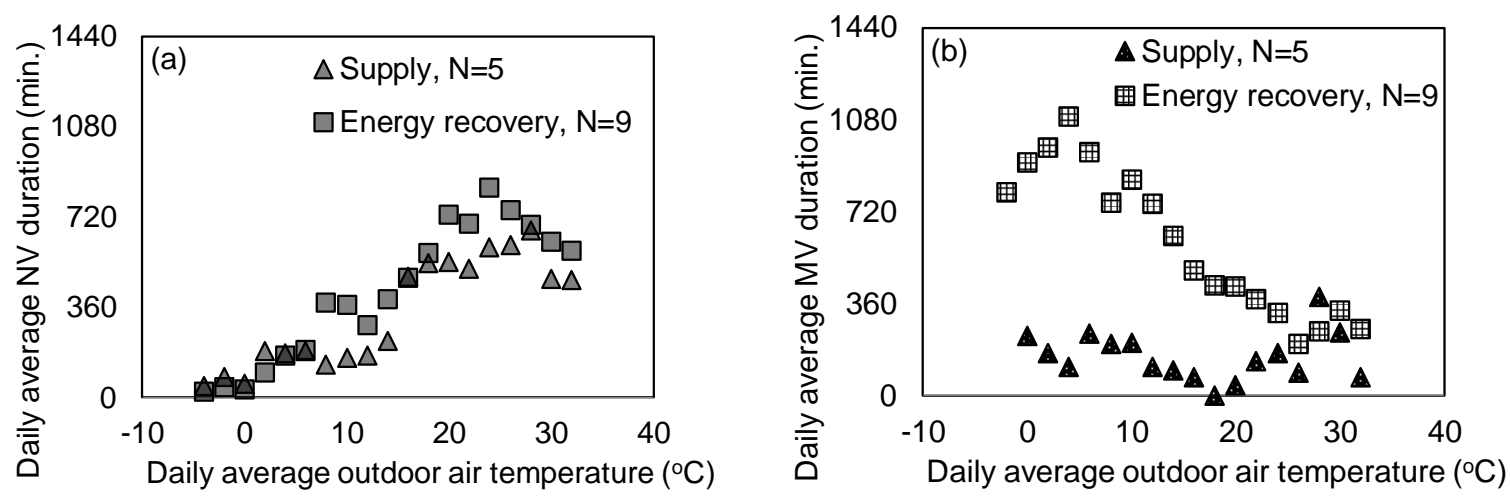

Figure 10. Comparison of average ventilation duration between supply and energy recovery ventilation systems in the cold climate region for (a) natural ventilation duration and (b) mechanical ventilation duration. 


\subsection{Usage patterns of natural and mechanical ventilation}

The ventilation durations shown in Figure 6 to Figure 10 were mean values of the daily durations. A large amount of information was lost during the averaging process. To further demonstrate the usage patterns of natural and mechanical ventilation, Figure 11 depicts the frequency distributions of the daily natural and mechanical ventilation durations for all the monitored apartments. It was surprising to find that for both types of ventilations the bins with the highest and second highest frequencies were the "0-120 minutes" bin and the "1320-1440 minutes" bin, and their frequencies were much higher than those of the remaining bins. A closer look at the data revealed that on most of the days, occupants of the monitored apartments either did not use ventilation at all, or they used ventilation all day, which shows that for most of the time, people were inactive in changing the ventilation status in their residences. The middle bins of Figure 11(a) have higher frequencies than those of Figure 11(b), indicating that people were more active in opening and closing windows than operating mechanical ventilation systems.
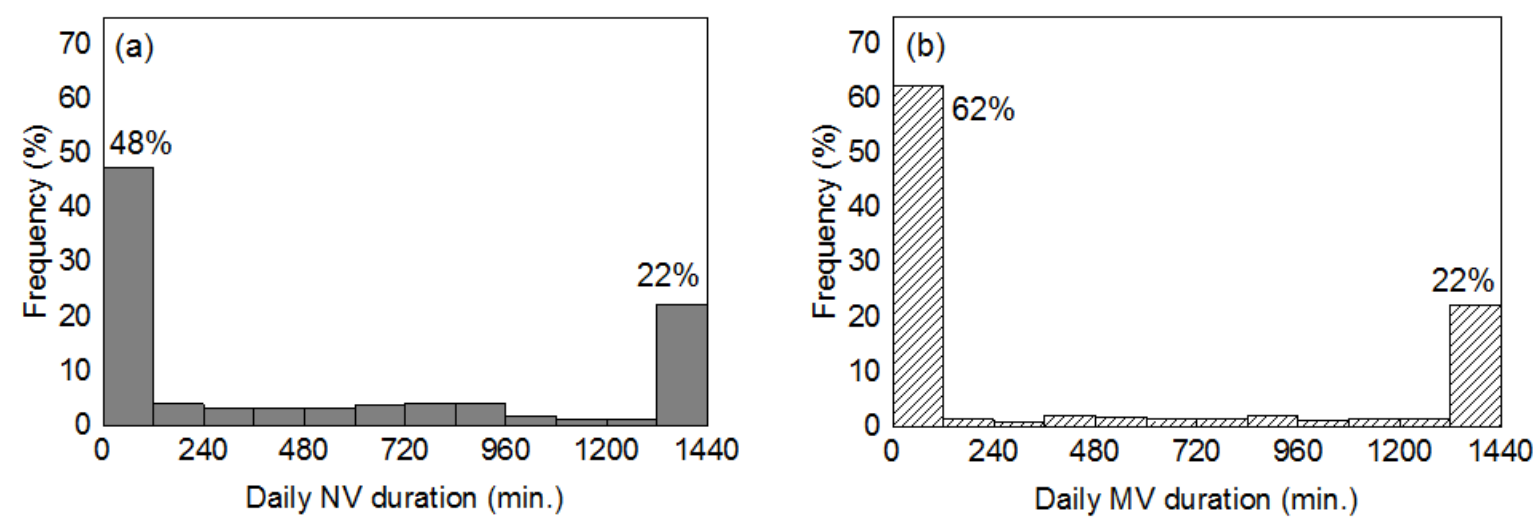

Figure 11. Frequency distribution of collected daily ventilation durations from all the monitored apartments for (a) natural ventilation and (b) mechanical ventilation.

For further examination of the "zero or all day" usage pattern, Figure 12 provides box plots of daily natural and mechanical ventilation durations in each monitored apartment. Large interfamily differences were found, especially for mechanical ventilation duration. For example, as demonstrated in Figure 12(b), among the 13 monitored apartments in the SC region, the median mechanical ventilation duration for four of the apartments was almost 1440 minutes, while the that for five of the apartments was near zero minutes. In the M and HSWW regions, only one household actively used mechanical ventilation. The natural ventilation duration also exhibited a large variation among households, although not as large as that of the mechanical ventilation duration. For instance, only one household in the SC region had a median daily NV duration longer than 70 minutes. In addition to the large inter-family difference, the day-to-day variation in ventilation duration for some families was also huge, as shown by the large ranges of some 
of the boxes in Figure 12.
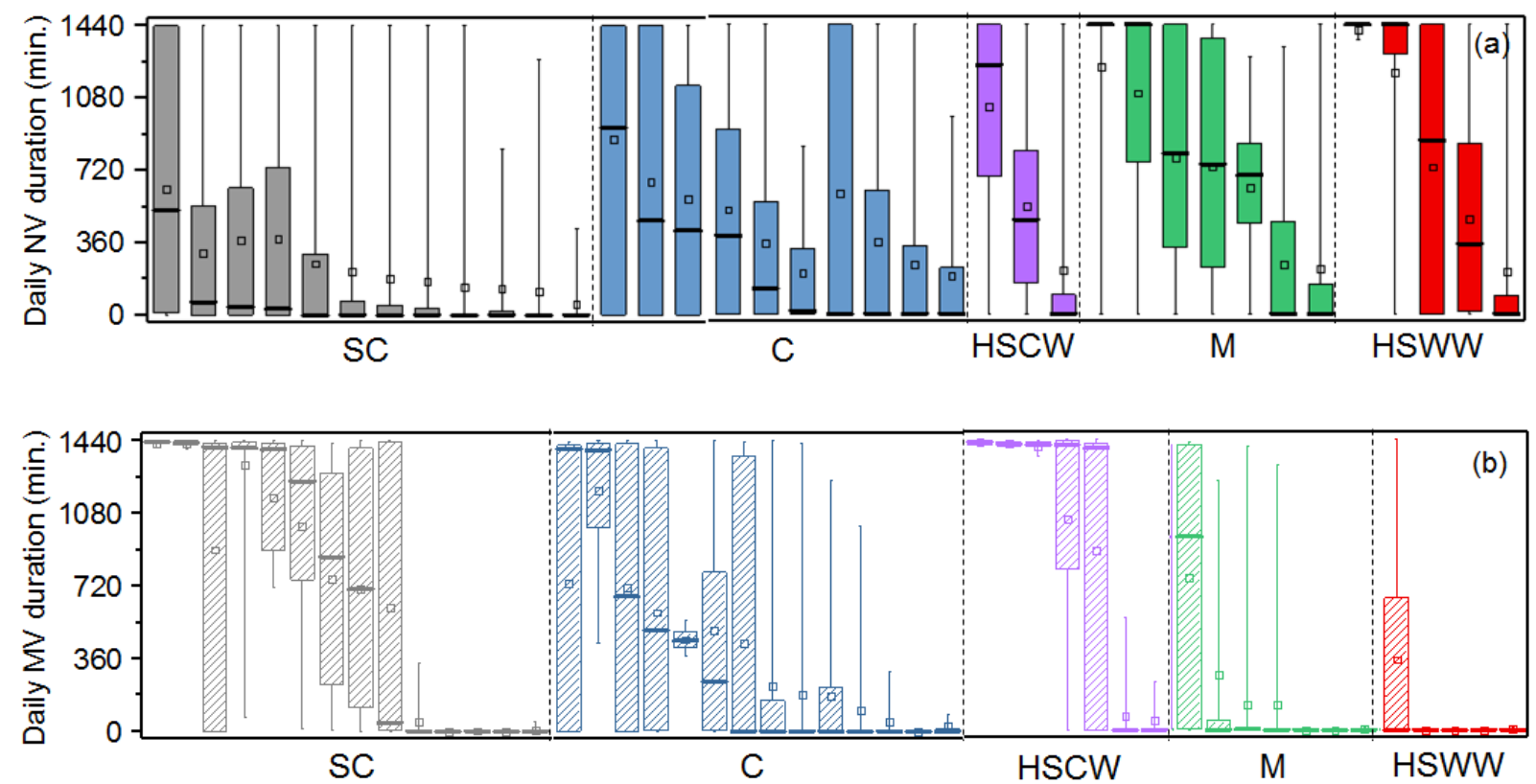

Figure 12. Box plots of ventilation duration in each monitored apartment for (a) natural ventilation and (b) mechanical ventilation. The horizontal lines and the dots within the boxes denote the median and mean values, respectively. The bottom and top of each box represent the $25^{\text {th }}$ and $75^{\text {th }}$ percentiles, respectively, while the lower and upper ends indicate the $5^{\text {th }}$ and $95^{\text {th }}$ percentiles, respectively.

\subsection{Questionnaire survey}

Subsections 3.1 to 3.4 analyze the objective data on ventilation behavior in the monitored households. As a comparison, this section also presents residents' subjective answers to questions about their ventilation patterns and the reasons behind their behavior.

\subsubsection{Ventilation choice under various conditions}

Figure 13 summarizes the occupants' ventilation preferences under various conditions as obtained from the questionnaire. The percentage of residents' ventilation choices under cold, neutral, and hot outdoor air temperatures are presented in Figure 13(a)--(c). The answers from residents in the SC, C, HSCW regions exhibited similar trends: when the outdoor environment was cold or hot, most of the residents in the SC, C, and HSCW regions preferred mechanical ventilation, whereas most of them preferred natural ventilation when the outdoor environment was thermally comfortable. In contrast, most residents in the M and HSWW regions preferred to ventilate their apartments naturally by opening windows, although the percentage of residents preferring natural ventilation slightly decreased in cold and hot outdoor climates. It should be noted that the questionnaire did not provide a quantitative definition of "cold," "neutral," and "hot" outdoor air temperatures, and thus respondents from different climate zones may have 
had their different understandings. The subjective answers from the questionnaire survey generally corresponded well with the monitored results, where the residents from the SC, C, and HSCW regions heavily used mechanical ventilation systems, while the primary means of ventilation for the M and HSWW regions was opening windows. However, one noticeable difference between the monitored and surveyed results was in people's ventilation patterns in a hot outdoor climate. According to the answers from the questionnaire, most residents preferred mechanical ventilation when the outdoor air temperature was high, but no rise in the actual mechanical ventilation duration was found as the daily average outdoor temperature increased.

(a) Cold outdoor environment

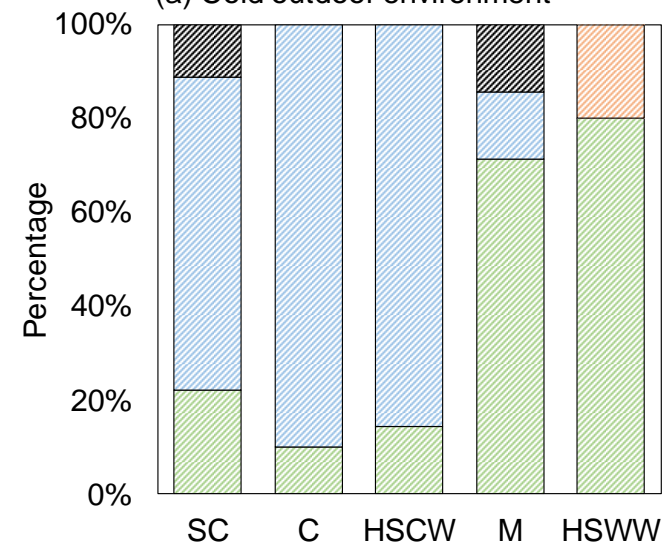

(c) Hot outdoor environment

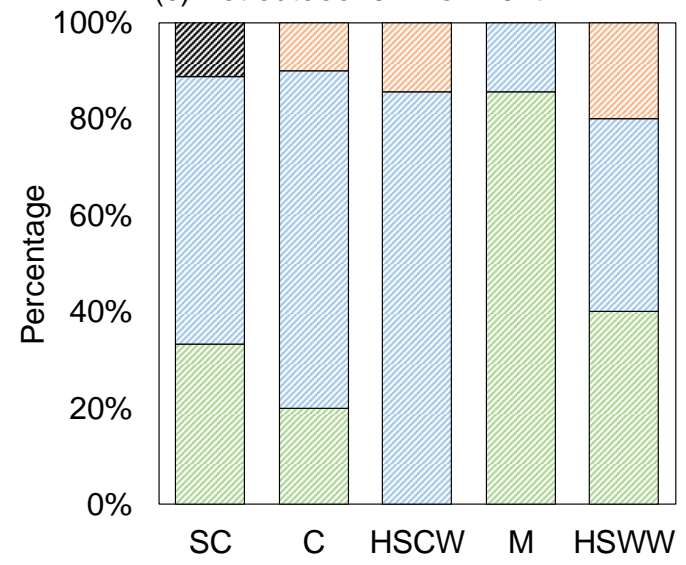

(b) Comfortable outdoor environment

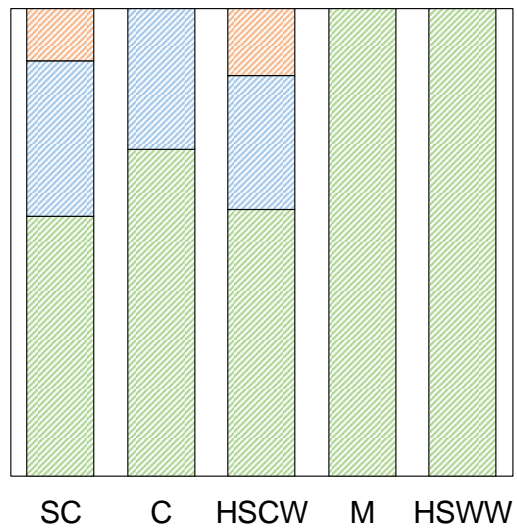

(d) Severely polluted outdoor environment

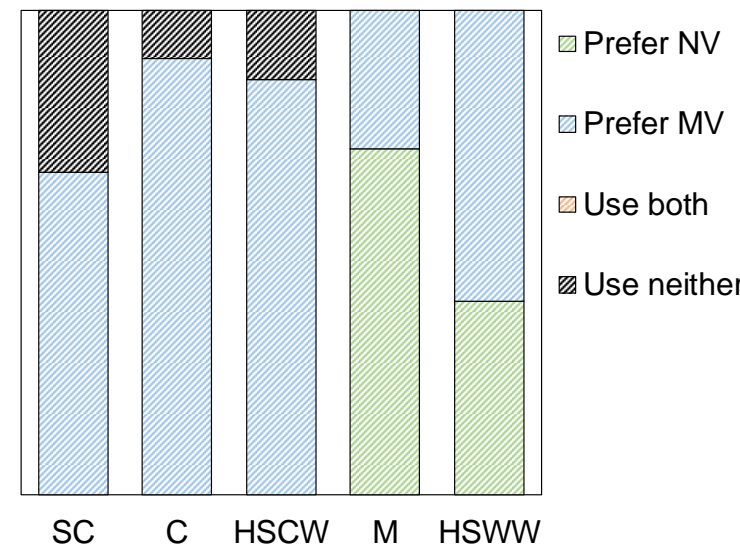

Figure 13. Answers about ventilation usage patterns in different climate zones under (a) cold outdoor climate conditions, (b) thermally comfortable outdoor climate conditions, (c) hot outdoor climate conditions, and (d) severely polluted outdoor environment.

When a dwelling is ventilated naturally by opening windows, outdoor pollutants can enter directly through the windows. The filter in a mechanical ventilation system can prevent some pollutants, such as particulate matter, from entering the building. Figure 13(d) presents the respondents' ventilation choices under severe outdoor pollution. Residents in the SC, C, and HSWW regions reported a strong preference for mechanical ventilation, and none of them preferred opening window for ventilation. As a comparison, $71.4 \%$ of the respondents in the $\mathrm{M}$ 
region and $40 \%$ in the HSWW region preferred natural ventilation even under polluted outdoor conditions. The difference may be due to the variations in pollutant level among regions. According to data from the China National Environmental Monitoring Station, Environmental Monitoring of China (http://datacenter.mep.gov.cn/), the 2017 annual average concentration levels in the cities that were monitored cities in the SC, C, HSCW, M, and HSWW regions were $63 \mathrm{ug} / \mathrm{m}^{3}, 70 \mathrm{ug} / \mathrm{m}^{3}, 44 \mathrm{ug} / \mathrm{m}^{3}, 22 \mathrm{ug} / \mathrm{m}^{3}$, and $35 \mathrm{ug} / \mathrm{m}^{3}$, respectively. Thus, the "heavy pollution" scenario perceived by residents of the M and HSWW regions may be much milder than the scenarios perceived by residents of other regions.

The results in Figure 13(d) indicate that ventilation behavior may be affected by the outdoor pollutant level. Similar conclusions were confirmed statistically in studies by Yao and Zhao [4] in Beijing, China, and Shi and Zhao [9] in Nanjing, China, where they found that the outdoor $\mathrm{PM}_{2.5}$ concentration negatively impacted the proportion of opened windows. Further work is necessary to quantitatively examine the impact of outdoor pollution on ventilation patterns.

\subsubsection{Reasons for not using natural and mechanical ventilation}

The final two questions in the questionnaire investigated the reasons for not using natural and mechanical ventilation. Because the answers did not exhibit a clear regional pattern, we summarized the responses from all climate regions in two pie charts. As shown in Figure 14(a), the highest-percentage reason for not using windows for ventilation was outdoor pollution $(42 \%)$, followed by thermal discomfort $(30 \%)$ and outdoor noise $(28 \%)$. For mechanical ventilation (Figure 14(b)), the three most frequently selected reasons were increased energy bills (33\%), system noise (30\%), and ineffectiveness of mechanical system in ventilation (23\%). Thermal discomfort was chosen by only $7 \%$ of the respondents, which may reflect the fact that the mechanical system generally did not cause thermal discomfort. Besides the provided options, some respondents indicated that the need for regular filter replacement was an obstacle to using the mechanical ventilation system. 
(a) Reasons for not using NV

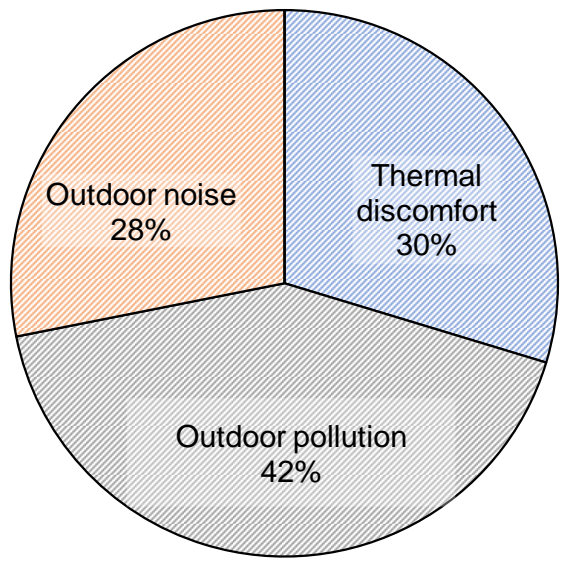

(b) Reasons for not using MV

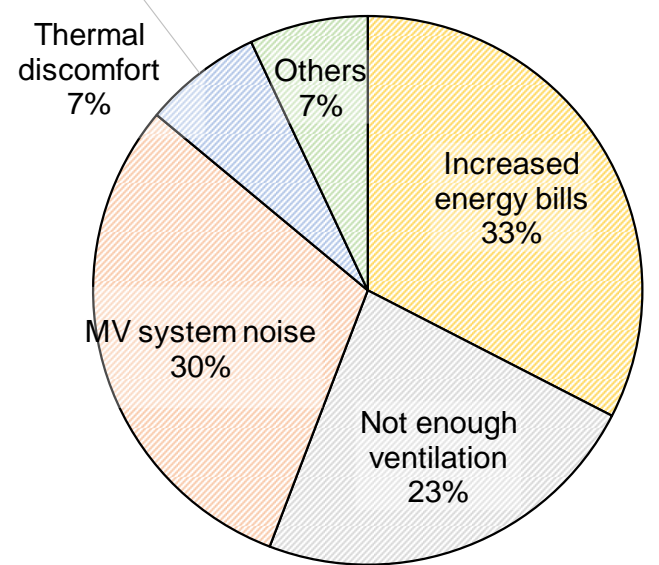

Figure 14. Reasons for not using (a) the windows for ventilation and (b) the mechanical system for ventilation

\section{Discussion}

\subsection{Thermal comfort, health, and energy saving as motivating factors for ventilation behavior}

The Results section demonstrated residents' natural and mechanical ventilation behavior in monitored apartments across China. The present section proposes three underlying motivations for ventilation behavior, which are thermal comfort, health, and energy saving.

Occupants' feeling of thermal comfort are based on instantaneous perception of thermal sensation. As a result, thermal comfort directly influences ventilation behavior. On the other hand, occupants do not immediately experience the adverse effects of insufficient ventilation on health, such as asthma, allergies, or sick building syndrome (SBS). However, people have learned from experience and public education that ventilation is beneficial to health. As a result, people's concern for their health is an indirect motivation for their ventilation behavior. A mechanical ventilation system causes less thermal discomfort than natural ventilation. Thus, occupants may be willing to use a mechanical ventilation system, if available, to meet their need for healthy indoor air at the cost of energy expenditure.

Figure 15 depicts people's ventilation behavior when they choose to either satisfy or sacrifice their needs for thermal comfort, health, and energy saving under cold, acceptable, and hot outdoor climate conditions. The figure assumes that people prioritize thermal comfort over health. As shown in Figure 15(a), when opening a window is the only available means ventilation, people would reduce natural ventilation to avoid thermal discomfort when the outdoor is too cold or too hot, without addressing the possible adverse health effects of insufficient ventilation. Such phenomenon is demonstrated in our previous analysis in homes without mechanical ventilation [28]. When mechanical ventilation is available in addition to 
natural ventilation, as shown in Figure 15(b), people would be willing to spend money on energy to increase mechanical ventilation usage and compensate for the reduction in natural ventilation. Finally, on occasions when the outdoor climate is suitable for natural ventilation, people would consider energy saving opportunities, reducing mechanical ventilation usage and using more natural ventilation.

(a) When only NV is available

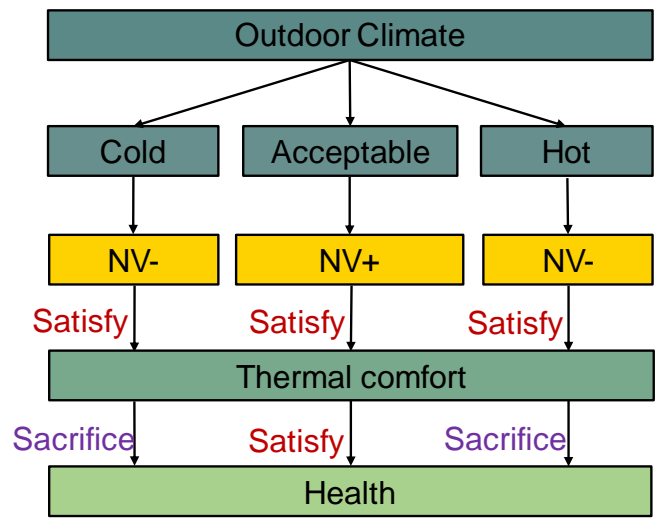

(b) When both NV and MV are available

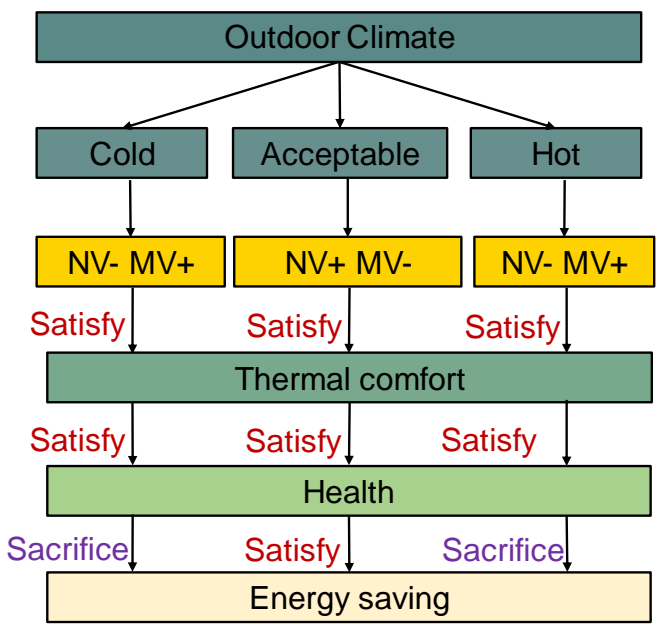

Figure 15. The impacts of prioritizing thermal comfort, health, or energy saving on ventilation behavior in cold, acceptable, and hot outdoor climates for (a) naturally ventilated buildings and (b) buildings with both natural and mechanical ventilation options.

\subsection{Strategies for designing and achieving healthy, thermally comfortable, and energy efficient ventilation in buildings}

Figure 16 provides a framework to design and achieve healthy, comfortable, and energyefficient ventilation in buildings. First, the amount of required ventilation is determined on the basis of the emission rates and health risks of pollutants. The emission rates of pollutants are dependent on specific features of the emission sources. For instance, indoor furniture continuously releases pollutants, but the emission rates may not be constant. There is evidence that the indoor formaldehyde concentration increases with air temperature [29-31]. The emission rates of some other pollutants, such as $\mathrm{CO}_{2}$, are related to the presence of occupants. Furthermore, some activities, such as cooking or cleaning, may lead to a sudden burst of pollutants. In addition to emission rates, the health risks posed by pollutants could be investigated by toxicology studies and epidemiological evidence, and then exposure limits could be set for the pollutants. Once the emission rates and health risks of pollutants have been determined, studying local climates could provide information about thermally comfortable natural ventilation duration. It is also necessary to know whether natural ventilation is sufficient to dilute the indoor pollutant concentration to an acceptable level. If not, mechanical ventilation 
should be used as an additional measure.

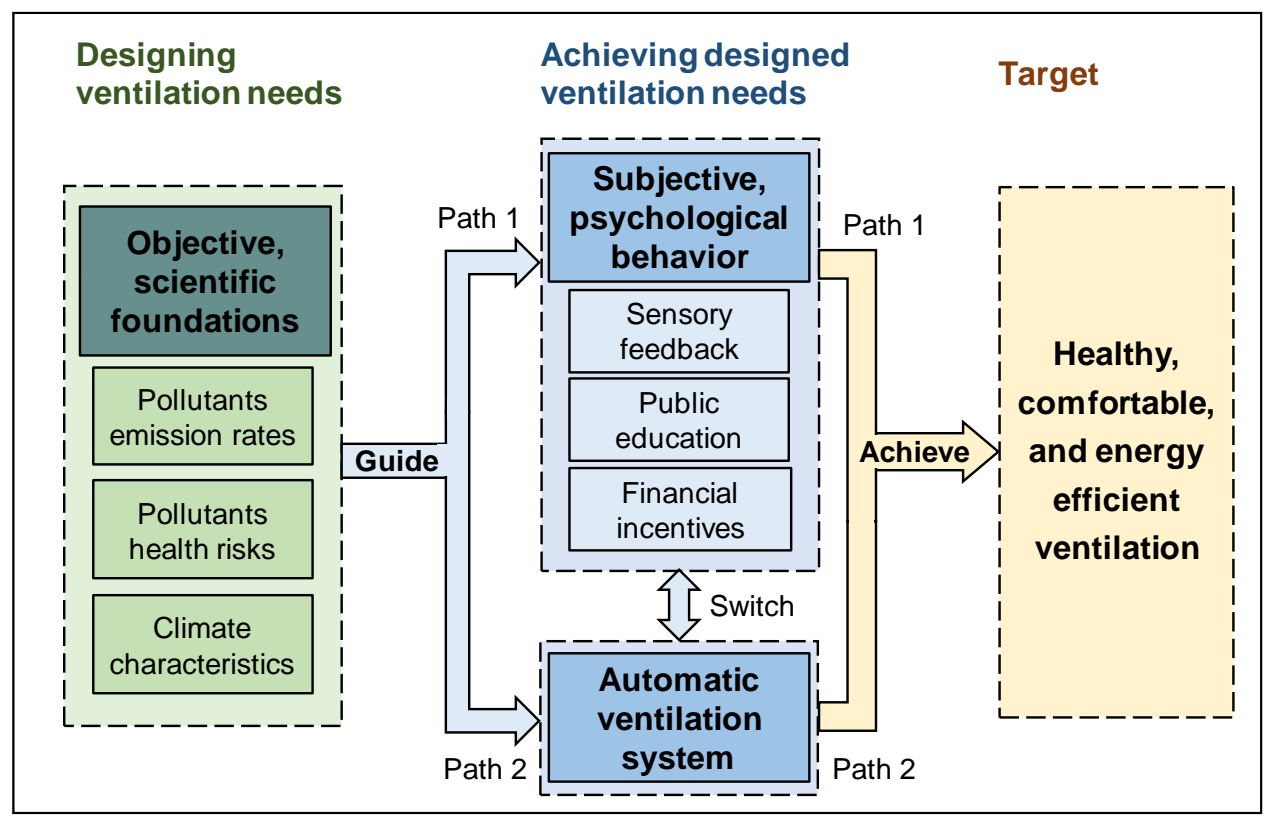

Figure 16. Framework for designing and achieving healthy, comfortable, and energy-efficient ventilation in buildings.

Once the ventilation requirement has been determined on the basis of objective scientific evidence, there are two ways of achieving the target. The first path is to guide the ventilation behavior of occupants by providing sensory stimuli (such as visual feedback on indoor pollutant levels and natural ventilation availability status), public education, and financial incentives. For example, Heeboll's study [20] in a Danish school found that visual feedback about indoor $\mathrm{CO}_{2}$ concentration had some impact on teachers' and pupils' window-opening behavior. As shown in Figure 12, since some of the households in the present study were inactive in using ventilation, it is necessary to increase their "ventilation awareness." In addition, there is potential for saving energy in northern households by increasing natural ventilation and decreasing the use of mechanical ventilation. As we can see in Figure 8, because of their long-term habits, northern residents used much less natural ventilation and more mechanical ventilation than southern residents, even under suitable climate conditions that were suitable for natural ventilation. An alternative way to meet ventilation needs is to develop and deploy an automatic ventilation system. The system would detect indoor pollutant levels and outdoor climate conditions and calculate the amount of ventilation required and the availability of thermally comfortable natural ventilation. The system would then decide whether natural, mechanical, or mixed ventilation should be used to achieve healthy, thermally comfortable, and energy efficient ventilation.

\subsection{Limitations}

This study only addressed the influence of thermal comfort on ventilation behavior. Besides the 
input from thermal sensation, stimulation from other senses, such as sight, hearing and smell, may also trigger ventilation behavior. For example, occupants might close a window upon seeing outdoor pollution or hearing outdoor noise, and they might open the window to eliminate an unpleasant smell. A comprehensive analysis of the impacts of all sensory inputs would further benefit our understanding of ventilation behavior. This paper described occupants' ventilation behavior, and a number of assumptions were made in order to explain this behavior. In our future work, we will seek to develop a model that predicts ventilation behavior and use the model to help achieve healthy, thermally comfortable, and energy-efficient ventilation in buildings. Only five and nine apartments of supply ventilation system and energy recovery system in cold climate region were included for the analysis of the behavioral difference in mechanical ventilation system. More samples are expected to provide statistically sound result.

\section{Conclusions}

This study investigated ventilation behavior in Chinese dwellings equipped with mechanical ventilation systems. Window-opening actions and mechanical ventilation system usage in 46 Chinese apartments in ten cities across five different climate zones were monitored for a year. Questionnaires were also distributed to understand residents' subjective choices. The following conclusions can be drawn from the analyses of the data.

1) The average durations for natural and mechanical ventilation of the monitored apartments were 660 minutes (11.0 hours) and 429 minutes ( 7.2 hours), respectively.

2) From north to south, as the climate became warmer, the natural ventilation duration increased, while the mechanical ventilation duration decreased.

3) Summer was the season with the longest natural ventilation duration and shortest mechanical ventilation duration, while the trend in winter was reversed.

4) With the increase in daily average outdoor air temperature, the duration of natural ventilation increased and the duration of mechanical ventilation decreased. However, in cold climate regions, the natural ventilation duration started to decrease when the daily average outdoor air temperature reached $24{ }^{\circ} \mathrm{C}$.

5) In cold climate regions, probably because of the resulting thermal discomfort, the usage of supply mechanical ventilation systems was much less than that of energy recovery ventilation systems.

6) Large variations in natural and mechanical ventilation durations existed among households. Occupants were inactive in changing the ventilation status in their dwellings.

On the basis of the ventilation behavior analyses, thermal comfort, health, and energy saving were proposed as the three motivations that drive ventilation behavior. In addition, a framework was proposed to design and achieve healthy, comfortable, and energy efficient ventilation in buildings. 


\section{Acknowledgement}

This research was partially supported by the national key project of the Ministry of Science and Technology, China, on "Green Buildings and Building Industrialization" through Grant No. 2016YFC0700500. We would like to express our gratitude to Prof. Kailiang Huang from Shenyang Jianzhu University; Prof. Yiwen Jian from Beijing University of Technology; Prof. Yuexia Sun, Prof. Jingjing Pei, Prof. Hejiang Sun, and Prof. Xiong Shen from Tianjin University; Prof. Haiguo Yin from Xi'an University of Architecture and Technology; Prof. Hongwei Tan from Tongji University, Dr. Yao Gao from Shenzhen Institute of Building Research Co., Ltd.; and all the graduate students for their help in discussing results and collecting data for the study.

\section{References}

[1] Q. Chen, Ventilation performance prediction for buildings: A method overview and recent applications, Building and Environment 44 (4) (2009) 848-858.

[2] ASHRAE, ASHRAE Handbook (SI), Fundamentals, American Society of Heating, Refrigerating and Air-conditioning Engineers, Inc., Atlanta, 2009.

[3] J. Sundell, H. Levin, W.W. Nazaroff, W.S. Cain, W.J. Fisk, D.T. Grimsrud, F. Gyntelberg, Y. Li, A.K. Persily, A.C. Pickering, J.M. Samet, Ventilation rates and health: Multidisciplinary review of the scientific literature, Indoor Air 21 (3) (2011) 191-204.

[4] M. Yao, B. Zhao, Window opening behavior of occupants in residential buildings in Beijing, Building and Environment 124 (2017) 441-449.

[5] H.B. Rijal, P. Tuohy, M.A. Humphreys, J.F. Nicol, A. Samuel, J. Clarke, Using results from field surveys to predict the effect of open windows on thermal comfort and energy use in buildings, Energy and Buildings 39 (7) (2017) 823-836.

[6] H.B. Rijal, Investigation of comfort temperature and occupant behavior in Japanese houses during the hot and humid season, Buildings 4 (3) (2014) 437-452.

[7] R. Andersen, V. Fabi, J. Toftum, S.P. Corgnati, B.W. Olesen, Window opening behaviour modelled from measurements in Danish dwellings, Building and Environment 69 (2013) 101 113.

[8] S. Pan, Y. Xiong, Y. Han, X. Zhang, L. Xia, S. Wei, J. Wu, M. Han, A study on influential factors of occupant window-opening behavior in an office building in China, Building and Environment 133 (2018) 41-50.

[9] S. Shi, B. Zhao, Occupants' interactions with windows in 8 residential apartments in Beijing and Nanjing, China, Building Simulation 9 (2) (2016) 221-231.

[10] V. Fabi, R.V. Andersen, S. Corgnati, B.W. Olesen, Occupants' window opening behaviour: A literature review of factors influencing occupant behaviour and models, Building and Environment 58 (2012) 188-198.

[11] S. Wei, R. Jones, P. de Wilde, Driving factors for occupant-controlled space heating in residential buildings, Energy and Buildings 70 (2014) 36-44. 
[12] S. Wei, R. Buswell, D. Loveday, Factors affecting ‘end-of-day' window position in a nonair-conditioned office building, Energy and Buildings 62 (2013) 87-96.

[13] S. Wei, T.M. Hassan, S.K. Firth, F. Fouchal, Impact of occupant behaviour on the energysaving potential of retrofit measures for a public building in the UK, Intelligent Buildings International 9 (2) (2017) 97-106.

[14] W. Liu, D. Yang, X. Shen, P. Yang, Indoor clothing insulation and thermal history: A clothing model based on logistic function and running mean outdoor temperature, Building and Environment, 135 (2018) 142-152.

[15] L. Lan, X.L. Qian, Z.W. Lian, Y.B. Lin, Local body cooling to improve sleep quality and thermal comfort in a hot environment, Indoor Air, 28 (1) (2018) 135-145.

[16] L. Lan, Z. Zhai, Z. Lian, A two-part model for evaluation of thermal neutrality for sleeping people, Building and Environment, 132 (2018) 319-326.

[17] H. Liu, Z. Lian, Z. Gong, Y. Wang, G. Yu, Thermal comfort, vibration, and noise in Chinese ship cabin environment in winter time, Building and Environment, 135 (2018) 104-111.

[18] H. Wang, L. Sun, H. Guan, S. Hu, Thermal environment investigation and analysis on thermal adaptation of workers in a rubber factory, Energy and Buildings, 158 (2018) 1625-1631. [19] J.S. Park, N.Y. Jee, J.W. Jeong, Effects of types of ventilation system on indoor particle concentrations in residential buildings, Indoor Air 24 (6) (2014) 629-638.

[20] A. Heebøll, P. Wargocki, J. Toftum, J, Window and door opening behavior, carbon dioxide concentration, temperature, and energy use during the heating season in classrooms with different ventilation retrofits-ASHRAE RP1624, Science and Technology for the Built Environment 0 (2018) 1-12.

[21] J. Gao, P. Wargocki, Y. Wang, Ventilation system type, classroom environmental quality and pupils' perceptions and symptoms, Building and Environment, 75 (2014) 46-57.

[22] J.S. Park, H.J. Kim, A field study of occupant behavior and energy consumption in apartments with mechanical ventilation, Energy and Buildings 50 (2012) 19-25.

[23] Ministry of Housing and Urban-Rural Development of the People's Republic of China, Thermal design code for civil building GB50176-2016, China Architecture and Building Press, Beijing, 2016. (In Chinese).

[24] United States Department of Energy, Whole house ventilation. https://www.energy.gov/energysaver/weatherize/ventilation/whole-house-ventilation.

[25] China Meteorological Administration, Division of Climatic Season QX/T 152-2012, China Meteorological Press, Beijing, 2012 (in Chinese).

[26] National Bureau of Statistics of China, Per capita disposable annual income of urban households. http://data.stats.gov.cn.

[27] ASHRAE, ANSI/ASHRAE Standard 55: Thermal Environmental Conditions for Human Occupancy, American Society of Heating, Refrigerating and Air-conditioning Engineers, Inc., Atlanta, 2017.

[28] D. Lai, S. Jia, Y. Qi, J. Liu, Window-opening behavior in Chinese residential buildings 
across different climate zones, Building and Environment 142 (2018) 234-243.

[29] X. Dai, J. Liu, Y. Yin, X. Song, S. Jia, Modeling and controlling indoor formaldehyde concentrations in apartments: On-site investigation in all climate zones of China, Building and Environment 127 (2018) 98-106.

[30] M. Guo, X. Pei, F. Mo, J. Liu, X. Shen, Formaldehyde concentration and its influencing factors in residential homes after decoration at Hangzhou, China, Journal of Environmental Sciences, 25 (5) (2013) 908-915.

[31] W. Liang, M. Lv, X. Yang, The combined effects of temperature and humidity on initial emittable formaldehyde concentration of a medium-density fiberboard, Building and Environment 98 (2016) 80-88. 